\title{
Cardiac pacing in incomplete atrioventricular block with atrial fibrillation
}

\author{
D. S. Reid, S. J. Jachuck, and C. B. Henderson \\ From the Department of Cardiology, Newcastle General Hospital, Newcastle upon Tyne
}

Three cases with a slow irregular ventricular response to atrial fibrillation, who benefited from cardiac pacing, are described; two had ischaemic heart disease, and one had cardiomyopathy. In the first case the slow ventricular response to atrial fibrillation was a result of incomplete atrioventricular nodal block, and in the other two His bundle electrograms demonstrated that the slow ventricular response was due to bilateral bundle-branch block. The association of atrial fibrillation and conduction delays in the atrioventricular node and bundlebranches is discussed. The value of His bundle recordings in the investigation of these cases is shown and the importance of cardiac pacing in treatment is stressed.

Cardiac pacing is now a generally accepted method of treatment in patients with complete heart block or bilateral bundle-branch block who have AdamStokes attacks or a low output syndrome leading to angina or cardiac failure. However, cardiac pacing is now also becoming more widely used in the treatment of patients with sinoatrial node disease ('sick sinus syndrome') who have disabling symptoms non-responsive to atropine or the sympathomimetic drugs (Bayley, 197I ; Easley and Goldstein, I971; Cheng, 1968). In some patients with sinus node disease the sinus bradycardia or sinoatrial block is associated with rapid supraventricular arrhythmias including atrial fibrillation with a rapid ventricular response - the bradycardia-tachycardia syndrome (Schulman et al., 1970). Atrial fibrillation with a slow ventricular rate is not a generally accepted feature of this syndrome, though Ferrer (I968) included this in her definition, unless drugs affecting atrioventricular nodal conduction have been given as in one of the cases described by Bayley (I971).

To our knowledge there has been no report of patients who have required pacing for atrial fibrillation with a slow irregular ventricular response and it is the purpose of this paper to report 3 such patients.

\section{Case reports}

\section{Case I}

A 69-year-old man who had sustained an acute myocardial infarction 24 hours previously was transferred to this hospital because of a slow heart rate associated with

Received 14 May 1973. hypotension. Intravenous atropine given before transfer had resulted in a paroxysm of ventricular tachycardia.

On admission there was no evidence of cardiac failure and the blood pressure was $105 / 50 \mathrm{mmHg}$. An electrocardiogram showed atrial fibrillation with an irregular ventricular response of 40 to 44 beats a minute and acute inferolateral myocardial infarction (Fig. I).

Over the subsequent three days the ventricular rate fell to 30 beats a minute and he developed cardiac failure, hypotension, and oliguria. A slow infusion of isoprenaline resulted in ventricular fibrillation which reverted to atrial fibrillation with a single DC shock. Transvenous demand cardiac pacing was started and over the next 5 days he gradually improved.

The pacemaker was removed on the Ioth day at which time he was in atrial fibrillation with a ventricular rate of 90 beats a minute (Fig. 2), and there was no evidence of cardiac failure. On discharge 5 weeks after admission and when seen 3 months later, he was well but in atrial fibrillation with a ventricular rate of 80 to 90 beats/minute.

\section{Case 2}

A 7I-year-old man was admitted with a one-year history of exertional chest pain and occasional syncope. In the week before admission syncope had occurred daily and he had become breathless on effort.

Examination revealed mild cardiac failure, left ventricular hypertrophy, a blood pressure of $150 / 80 \mathrm{mmHg}$, and a slow irregular pulse.

An electrocardiogram showed atrial fibrillation with an irregular ventricular response of 50 beats a minute, complete right bundle-branch block, a mean frontal QRS axis to the left with an initial vector directed inferiorly suggesting left anterior hemiblock (Fig. 3). A chest $x$-ray showed a cardiothoracic ratio of 60 per cent and promi- 


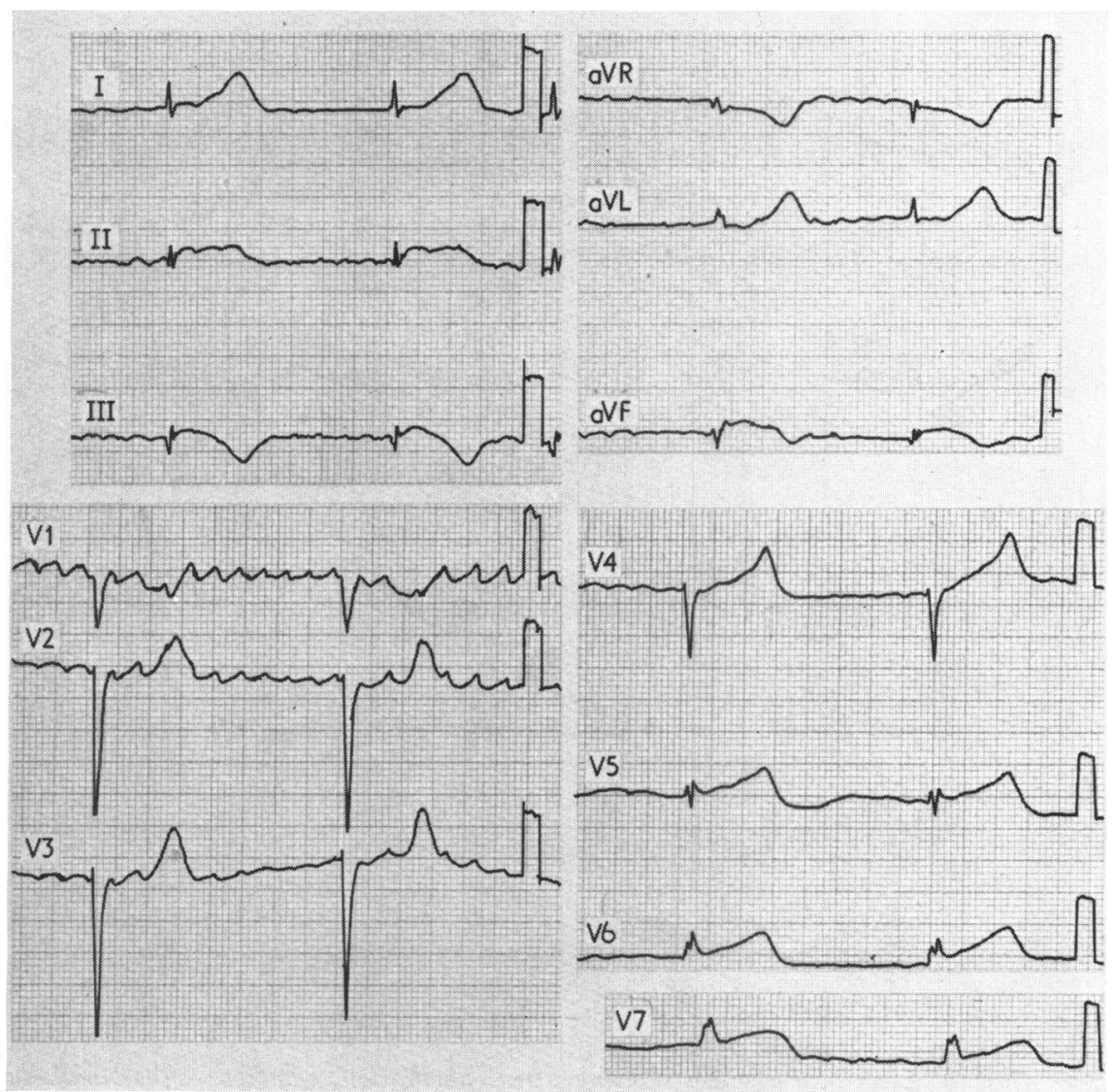

FIG. I Case I. Electrocardiogram 24 hours after myocardial infarction.

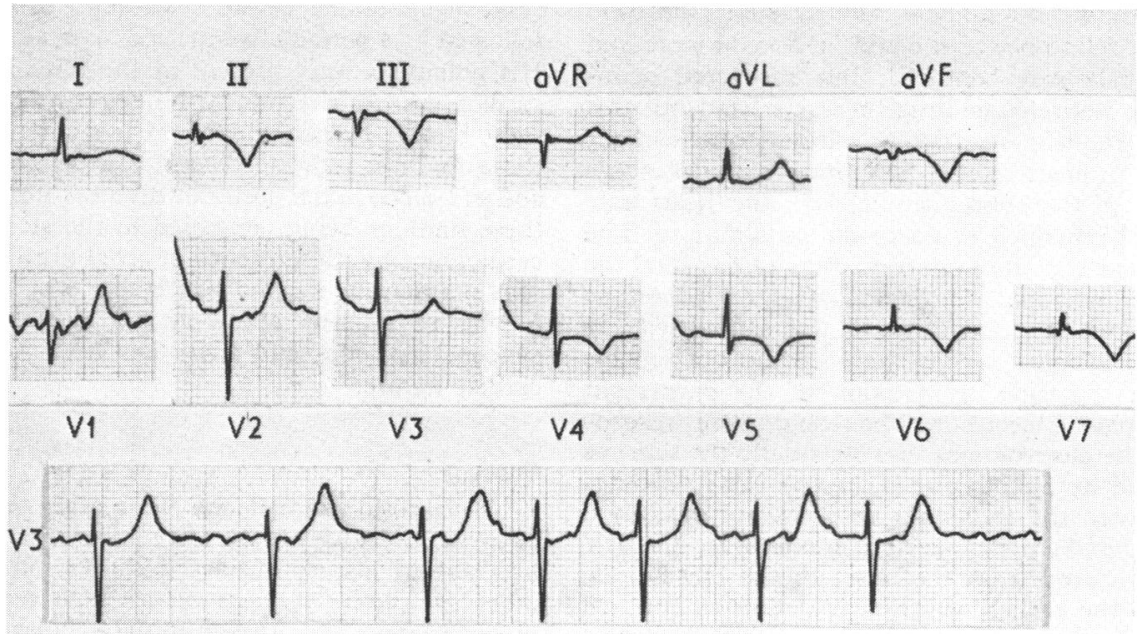

FIG. 2 Case I. Electrocardiogram I4 days after myocardial infarction. 


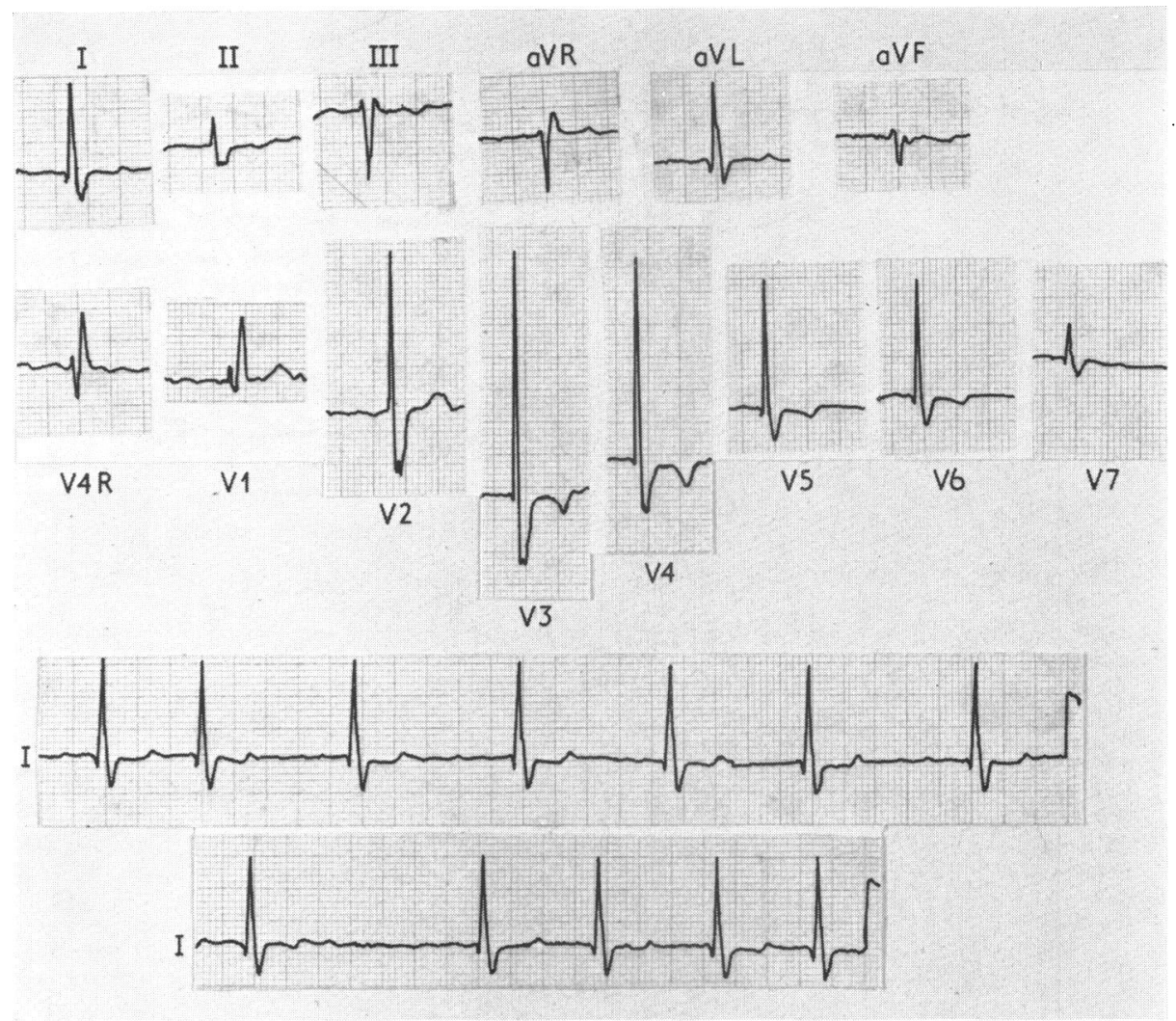

FIG. 3 Case 2. Electrocardiogram showing atrial fibrillation, complete right bundle-branch block, and left anterior hemiblock.

nence of the upper lobe veins. Shortly after admission the heart rate fell to between 6 and 20 beats/minute and he became pale and confused, but recovered spontaneously. An isoprenaline infusion was started but this resulted in frequent ventricular extrasystoles without any increase in heart rate. A temporary pacemaker was inserted and in the subsequent 2 days the heart rate increased and remained at 60 to 90 beats/minute. The pacemaker was therefore removed after 12 days and the patient was discharged. However, one month later he had a recurrence of syncope and he was readmitted.

Electrophysiological studies were carried out on this admission at the time of insertion of the permanent transvenous pacing electrode. The technique for recording His bundle electrograms was essentially the same as that described by Scherlag et al. (1969). All recordings were made with the frequency response set at 40-500 cycles/second and a paper speed of $100 \mathrm{mmsec}$. The HV time was measured from the onset of the His bundle deflection to the earliest ventricular deflection (normal 35-55 msec).

The HV time was normal in the conducted beats (40 $\mathrm{msec}$ ) but there was intermittent block distal to the bundle of His (Fig. 4a) and at times 2: I post $\mathrm{H}$ block
(Fig. 4b). Sudden cessation of ventricular pacing was followed by a period of ventricular asystole during which His potentials were present in the His bundle electrocardiogram. As the standard electrocardiogram showed right bundle-branch block and left anterior hemiblock these findings indicate second-degree block Mobitz II and $2: \mathrm{I}$ block in the posterior division of the left bundle, these findings being concealed in the standard electrocardiogram by the presence of atrial fibrillation.

A permanent demand pacemaker was implanted and in the 12 months follow-up he has had no further syncopal episodes and there has been no evidence of cardiac failure.

\section{Case 3}

A 68-year-old woman was first admitted to another hospital in January 1969 after a syncopal episode. She had a short history of chest tightness on effort but no other symptoms of heart disease. On examination the blood pressure was $160 / 90 \mathrm{mmHg}$, pulse was irregular at 46 beats a minute, and there was no evidence of heart failure. Electrocardiograms showed $2: I$ and $3: 1$ sinoatrial block with a junctional escape rhythm, at times 


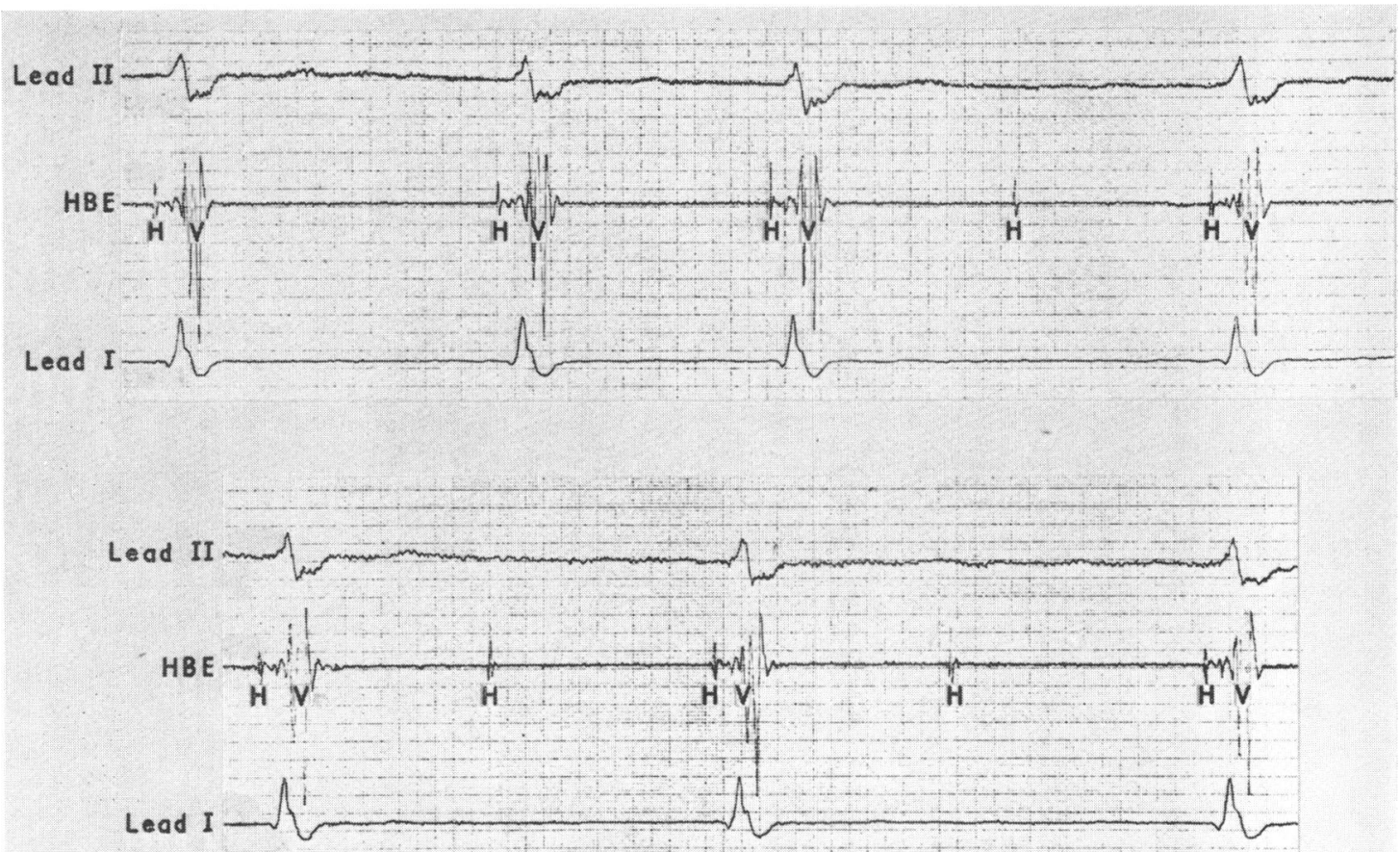

FIG. 4 Case 2. His bundle electrogram recorded at $100 \mathrm{~mm} / \mathrm{sec}$ with simultaneous leads $I$ and II. (a) Irregular His response to atrial fibrillation and Mobitz II post $H$ block. HV normal in conducted beats ( $40 \mathrm{msec}$ ). (b) $2: 1$ block distal to bundle of His. HBE = His bundle recording; $H=H i$ bundle electrogram; $V=$ ventricular electrogram.

with retrograde $P$ waves (Fig. 5a). Chest $x$-ray showed cardiac enlargement. She had no further syncopal episodes and within 2 days the sinus rhythm was resumed with a normal PR interval $(0.18 \mathrm{sec})$ and complete left bundle-branch block (Fig. 5b).

In July I97I she was admitted to the same hospital with cardiac failure. Electrocardiograms on this admission showed atrial fibrillation with an irregular ventricular response of Ioo beats/min and complete left bundlebranch block. She was treated with digoxin and diuretics and improved to some extent.

She was initially seen at this hospital in November 1972 because of breathlessness on minimal effort that had persisted since July I97I. The digoxin had been stopped several months before this admission because of a slow ventricular rate and isoprenaline had been given in a dose of $60 \mathrm{mg}$ 8-hourly without any improvement in the symptoms or heart rate. Examination showed that there was cardiac failure and the heart rhythm was irregular with a rate of 43 beats a minute. There was left ventricular hypertrophy and an apical pansystolic murmur. An electrocardiogram showed atrial fibrillation with a slow irregular ventricular response and complete left bundle-branch block (Fig. 5c). $X$-ray showed a cardiothoracic ratio of $\mathbf{7 5}$ per cent.
A His bundle electrogram (Fig. 6) demonstrated a prolonged HV time ( $60 \mathrm{msec}$ ) in the conducted beats and variable post $H$ block; at times $2: I$ post $H$ block at other times post $\mathrm{H}$ block without prolongation of the $\mathrm{HV}$ time in the preceding beats as is usual in Mobitz type II second-degree block (Narula and Samet, 1970).

A Devices permanent demand pacemaker was inserted, and in the 6 months after this there has been no clinical evidence of heart failure.

\section{Discussion}

The drug resistant bradycardias which require cardiac pacing usually fall into two groups. In the first group the bradycardia is due to atrioventricular node, His bundle, or bilateral bundle-branch disease resulting in a slow but regular idioventricular or junctional rhythm even in the presence of atrial fibrillation. In the other group, the bradycardia is due to sinoatrial node disease causing sinus bradycardia or varying degrees of sinoatrial block. This second group may be associated with atrial fibrillation in which the ventricular response is rapid and irregular. The 3 cases reported do not fall clearly 


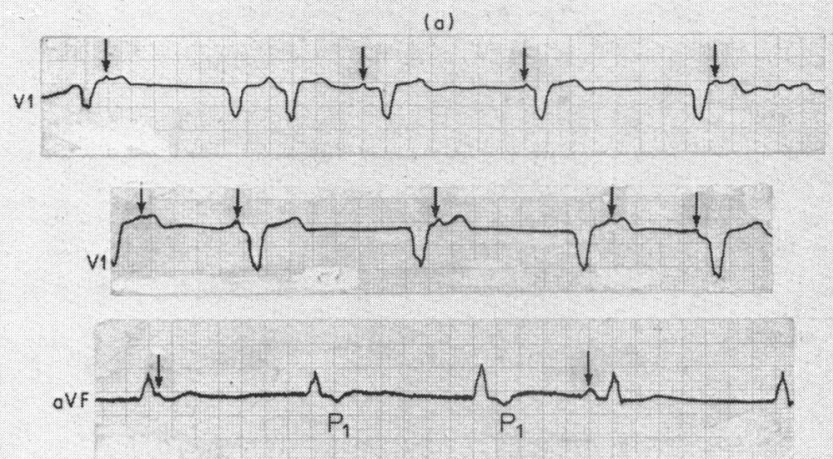

(b)
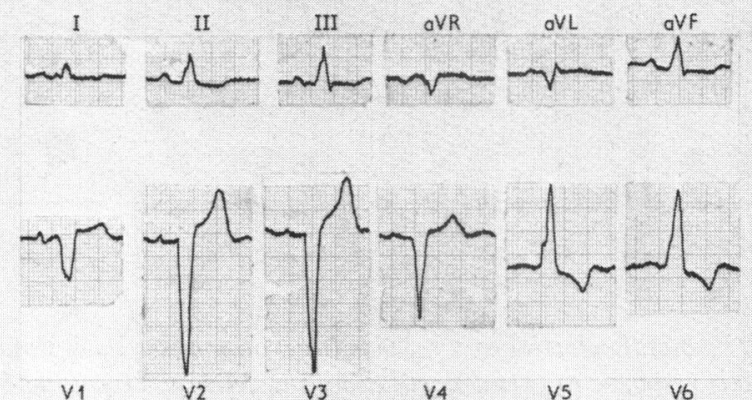

V3 $\quad V^{3}$

V5

V6

(c)
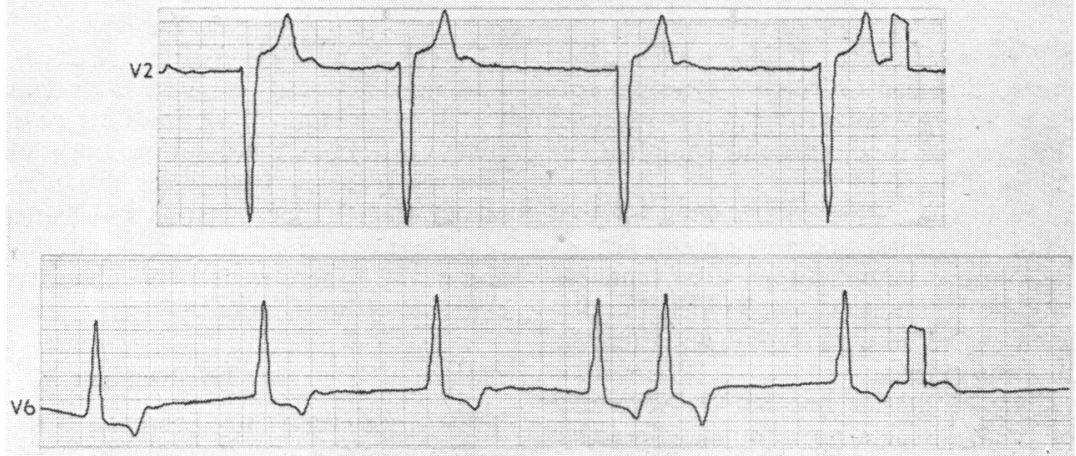

FIG. 5 Case 3. (a) I7-I8 fanuary 1969. $V_{1}$ 2:I to 3:I $S A$ block, $A V$ dissociation. aVF-AV dissociation due to slow atrial rate with retrograde $P$ waves $\left(P_{1}\right)$ and a capture beat (arrows indicate $P$ waves). (b) 19 fanuary 1969. Sinus rhythm and complete left bundle-branch block. (c) November 1972. Atrial fibrillation with a slow ventricular rate. Left bundle-branch block. 


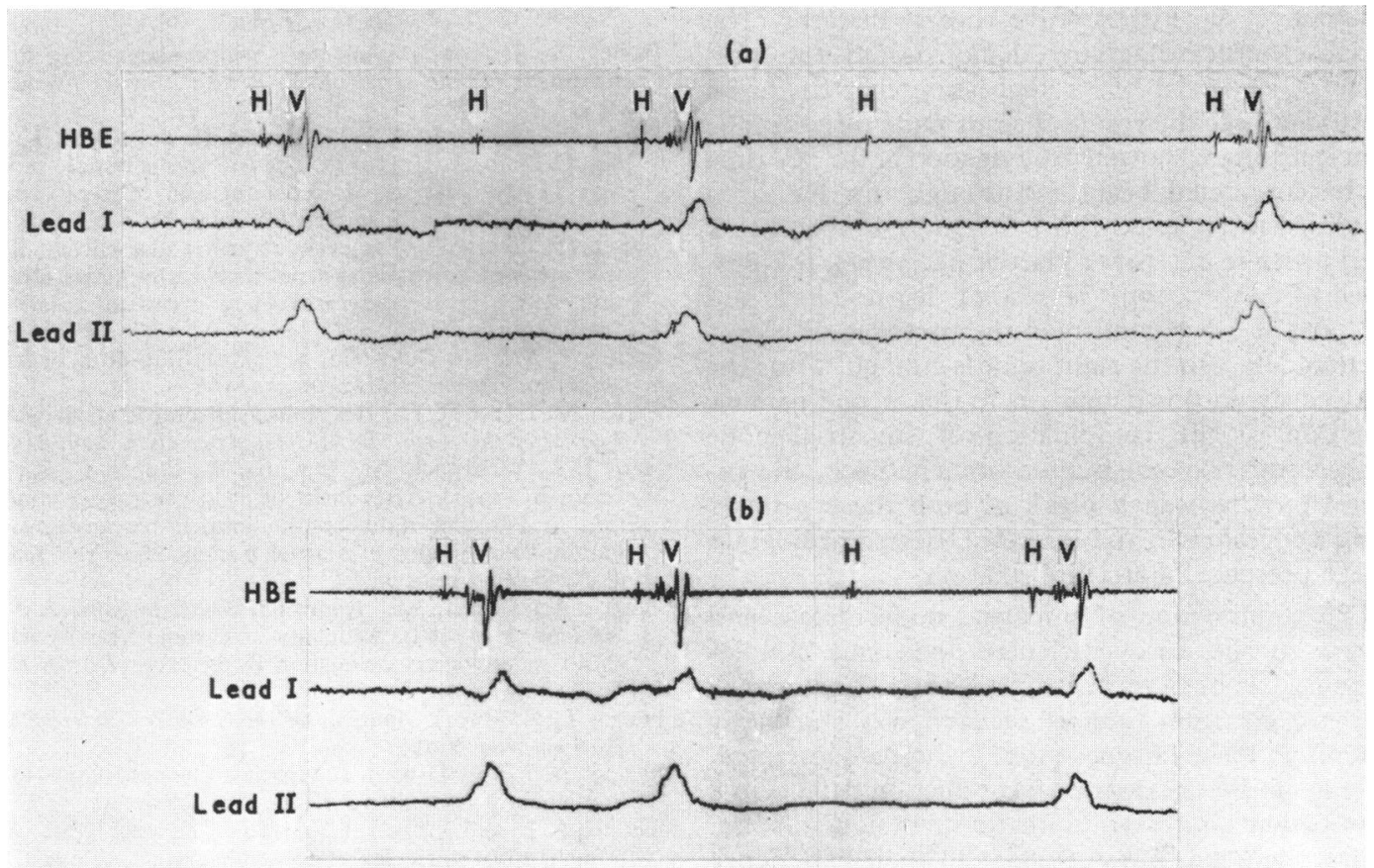

FIG. 6 Case 3. His bundle electrogram. (a) $2: I$ post $H$ block. (b) $H V$ prolonged in conducted beats (6o msec) Mobitz II second-degree block.

into either group, as the atrial fibrillation was associated with a slow but irregular ventricular response. This suggests that there may be a third group of patients that may require cardiac pacing in which the mechanism of production of the bradycardia is different from the above groups.

In the first case the bradycardia followed an acute inferior transmural myocardial infarction. The artery to the sinoatrial node arises from the proximal part of the right coronary artery in 55 to 65 per cent of the population (James, I96I ; Kennel and Titus, 1972a). It, therefore, seems likely that the mechanism of production of the atrial fibrillation was proximal right coronary artery occlusion resulting in sinoatrial node ischaemia or infarction. However, it has also been suggested that atrial fibrillation in myocardial infarction may be due to raised left atrial pressure secondary to left ventricular failure (Lown, Kosowsky, and Klein, 1969). It seems unlikely that this was the cause in this patient as the atrial fibrillation preceded the onset of left ventricular failure. It has also been shown that the right coronary artery supplies the artery to the atrioventricular node in 83 to 90 per cent of the population (James, 196I; Kennel and Titus, 1972b). Thus right coronary occlusion could result in atrio- ventricular nodal ischaemia leading to incomplete atrioventricular nodal block and thus a slow irregular ventricular response to atrial fibrillation.

In the second patient ischaemic heart disease was also the probable basic aetiology of the arrhythmia. The atrial fibrillation in this case could, therefore, be a manifestation of sinoatrial node disease though this is difficult to prove in established atrial fibrillation by electrophysiological studies such as atrial pacing (Mandel et al., I97I; Narula, Samet, and Javier, 1972). The cause of the slow irregular ventricular response to the atrial fibrillation, however, was clearly demonstrated as bilateral bundle-branch block. Thus the arrhythmia in this case was due to a combination of atrial disease and bilateral bundlebranch block.

The underlying cause of the arrhythmia in the third patient has not been established. The brief history of chest tightness on effort may indicate that coronary artery disease was the underlying cause though anginal-type pain can occur in patients with slow heart rates without ischaemic heart disease (Harris et al., 1969).

Cardiomyopathy, therefore, seems a more likely explanation of the cardiac failure and arrhythmia in the absence of any clear evidence of ischaemic, 
rheumatic, or hypertensive heart disease. The initial electrocardiograms demonstrated the presence of sinoatrial block suggesting that the atrial fibrillation was the result of sinus node disease. The His electrogram showed prolongation of the $\mathrm{HV}$ time in the conducted beats and though this has been described in patients with left bundle-branch block (Berkowitz et al., 197I ; Haft et al., 1971), the presence of Mobitz type II second-degree block and 2: I post $\mathrm{H}$ block confirmed the presence of a conduction defect in the right bundle-branch. Thus the bradycardia in this patient, as in the second patient, was due to the combination of sinoatrial node disease and bilateral bundle-branch block, the bilateral bundle-branch block in both these patients being concealed in the standard electrocardiogram by the presence of atrial fibrillation.

The combination of sinoatrial node disease and disease in the atrioventricular node and bundlebranches has been recorded previously. That it may be more common than is realized was shown by Rosen and his colleagues (1971) who demonstrated, by His bundle electrograms, conduction defects in 8 of 15 patients with symptomatic sinus node disease. They concluded, however, that in their experience conduction defects in patients with sinoatrial node disease did not appear to be serious. More recently, Rubenstein et al. (1972) showed that 33 of their 56 patients with sick sinus syndrome had evidence of a conduction disturbance in the atrioventricular node or in the bundle-branches though none of their patients had second or third-degree block. Our three patients show that sinus node disease may be associated with serious conduction disturbances in the atrioventricular node or bundle-branches, and that His bundle electrograms may be necessary to demonstrate the severity of the conduction disturbance in the presence of slow atrial fibrillation. The importance of demonstrating this association is shown by the fact that these patients did not improve when treated with digoxin, isoprenaline, and atropine, but responded dramatically to ventricular pacing. Thus patients who have a slow ventricular response to atrial fibrillation and who have dizziness, syncope, cardiac failure, or angina may not respond to drug therapy but improve if permanent ventricular pacing is instituted.

\section{References}

Bayley, T. J. (197I). Long-term ventricular pacing in the treatment of sino-atrial block. British Medical fournal, 3, 456.

Berkowitz, W. D., Lau, S. H., Patton, R. D., Rosen, K. M., and Damato, A. N. (1971). The use of His bundle recordings in the analysis of unilateral and bilateral bundle branch block. American Heart fournal, 81, 340.

Cheng, T. O. (1968). Transvenous ventricular pacing in the treatment of paroxysmal atrial tachyarrhythmias alternating with sinus bradycardia and standstill. American fournal of Cardiology, 22, 874 .

Easley, R. M., and Goldstein, S. (197I). Sino-atrial syncope. American fournal of Medicine, 50, I66.

Ferrer, M. I. (1968). The sick sinus syndrome in atrial disease. fournal of the American Medical Association, 206, 645.

Haft, J. I., Weinstock, M., DeGuia, R., Gupta, P. K., and Fano, A. (197I). Assessment of atrio-ventricular conduction in left and right bundle branch block using His bundle electrograms and atrial pacing. American fournal of Cardiology, 27, 474 .

Harris, A., Davies, M., Redwood, D., Leatham, A., and Siddons, H. (1969). Aetiology of chronic heart block. A clinico-pathological correlation in 65 cases. British Heart fournal, 31, 206.

James, T. N. (1961). Anatomy of the Coronary Arteries. Paul Hoeber, New York.

Kennel, A. J., and Titus, J. L. (1972a). The vasculature of the human sinus node. Mayo Clinic Proceedings, 47, 556

Kennel, A. J., and Titus, J. L. (1972b). The vasculature of the human atrioventricular conduction system. Mayo Clinic Proceedings, 47, 562.

Lown, B., Kosowsky, B. D., and Klein, M. D. (1969). Pathogenesis, prevention and treatment of arrhythmias in myocardial infarction. Circulation, 39, Suppl. IV, 26r.

Mandel, W., Hayakawa, H., Danzig, R., and Marcus, H. S. (I97I). Evaluation of sino-atrial node function in man by overdrive suppression. Circulation, 44, 59.

Narula, O. S., and Samet, P. (1970). Wenckebach and Mobitz type II A-V block due to block within the His bundle and bundle branches. Circulation, 4I, 947.

Narula, O. S., Samet, P., and Javier, R. P. (1972). Significance of the sinus-node recovery time. Circulation, 45, 140.

Rosen, K. M., Loeb, H. S., Sinno, M. Z., Rahimtoola, S. H., and Gunner, R. W. (197I). Cardiac conduction in patients with symptomatic sinus node disease. Circulation, 43,836 .

Rubenstein, J. L., Schulman, C. L., Yurchak, P. M., and DeSanctis, R. W. (1972). Clinical spectrum of the sick sinus syndrome. Circulation, 46, 5 .

Scherlag, B. J., Lau, S. H., Helfant, R. H., Berkowitz, W. D., Stein, E., and Damato, A. N. (1969). Catheter technique for recording His bundle activity in man. Circulation, 39, 13.

Schulman, C. L., Rubenstein, J. J., Yurchak, P. M., and DeSanctis, R. W. (1970). The sick sinus syndrome clinical spectrum. Circulation, 41 and 42, Suppl. III, 42.

Requests for reprints to Dr. D. S. Reid, Department of Cardiology, Newcastle General Hospital, Westgate Road, Newcastle upon Tyne NE4 6BE. 